Recepción: 13 / 02 / 2018

Aceptación: 09 / 04 / 2018

Publicación: 05 / 06 / 2018

Ciencias económicas y empresariales

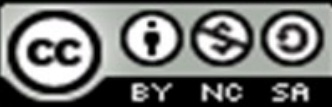

Artículo de Investigación

\title{
Las estrategias comerciales para la captación de clientes del sector artesanal en el cantón Naranjito-Ecuador en el año 2017-2018
}

Commercial strategies for attracting clients from the artisanal sector in the Naranjito-Ecuador canton in the year 2017-2018

Estratégias comerciais para atrair clientes do setor artesanal no cantão Naranjito-Equador no ano 2017-2018

Jinsop E. Gamboa-Poveda ${ }^{\mathrm{I}}$ jgamboap@unemi.edu.ec

Germánico R. Tovar-Arcos ${ }^{\mathrm{II}}$ gtovara@unemi.edu.ec

Gil M. Armijo-Borja ${ }^{\mathrm{III}}$ garmijob@unemi.edu.ec Hugo E. Hidalgo-Hidalgo IV hhigalgoh@unemi.edu.ec

Correspondencia: jgamboap@unemi.edu.ec

\footnotetext{
${ }^{\text {I }}$ Magister en Administración y Dirección de Empresas, Contador Público Autorizado Universidad Estatal de Milagro, Milagro, Ecuador.

II Magister en Diseño y Gestión de Marca, Magister en Gestión de la Educación Mención en Educación Básica, Técnico Superior En Programación De Sistemas, Universidad Estatal de Milagro, Milagro, Ecuador.
} 


\section{titulo}

${ }^{\text {III }}$ Magister en Derecho Penal y Criminología, Especialista en Derecho Penal y Justicia Indígena, Diploma Superior en Currículo por Competencias, Abogado de los Tribunales y Juzgados de la República del Ecuador, Universidad Estatal de Milagro, Milagro, Ecuador.

IV Magister en Administración y Dirección de Empresas, Diploma Superior en Diseño Curricular por Competencias, Tecnólogo en Marketing y Ventas, Universidad Estatal de Milagro, Milagro, Ecuador. 


\title{
Resumen
}

El presente artículo hace referencia al uso de estrategias comerciales que debería utilizar el gremio artesanal del cantón Naranjito y que carece de eficiencia por lo que requiere un análisis y refuerzo para mejorar y garantizar la satisfacción del consumidor al mismo tiempo la sostenibilidad del negocio en este nicho de mercado, y que se va a ver reflejado en la captación de clientes. La metodología que empleó la investigación fue de tipo documental, con el propósito de aportar nuevos conocimientos. Para ello se realizó un estudio bibliográfico de las acciones que permiten que el artesano tenga un lineamiento en la investigación de mercado para la captación de clientes utilizando estrategias comerciales que le permitan llegar al público con las artesanías. La población la constituyeron 164 artesanos de los cuales 45 son calificados. Del análisis de la información se pudo constatar que es necesario aplicar un plan de capacitación de estrategias comerciales y técnicas de ventas del mercado dirigido al sector manufacturero del Cantón Naranjito.

Palabras clave: gremio artesanal; estrategias; captación; comercializar.

\begin{abstract}
This article refers to the use of commercial strategies that should be used by the artisanal guild of Canton Naranjito and that lacks efficiency, so it requires analysis and reinforcement to improve and guarantee consumer satisfaction at the same time the sustainability of the business in this niche market, and that will be reflected in the recruitment of customers. The methodology used by the research was documentary, with the purpose of providing new knowledge. To this end, a bibliographic study was carried out of the actions that allow the artisan to have a guideline in market research for attracting clients using commercial strategies that allow them to reach the public with handicrafts. The population was made up of 164 artisans of whom 45 are qualified. From the analysis of the information, it was found that it is necessary to apply a training plan for commercial strategies and sales techniques of the market aimed at the manufacturing sector of the Canton Naranjito.
\end{abstract}

Keywords: craft guild; strategies; catchment; market. 


\section{Resumo}

Este artigo refere-se ao uso de estratégias de negociação você deve usar a aliança ofício Cantón Naranjito e carece de eficiência exigindo análise e reforço para melhorar e garantir a satisfação do cliente ao mesmo tempo a sustentabilidade do negócio neste nicho mercado, e isso se refletirá no recrutamento de clientes. A metodologia utilizada pela pesquisa foi documental, com o objetivo de fornecer novos conhecimentos. Para tanto, foi realizado um estudo bibliográfico das ações que permitem ao artesão orientar-se em pesquisas de mercado para atração de clientes, utilizando estratégias comerciais que lhes permitam atingir o público com o artesanato. A população foi composta por 164 artesãos, dos quais 45 são qualificados. A partir da análise das informações constatou-se que é necessário aplicar um plano de treinamento para estratégias comerciais e técnicas de vendas do mercado voltado ao setor manufatureiro do cantão Naranjito.

Palavras chave: aliança de ofício; estratégias; bacia hidrográfica; mercado.

\section{Introducción}

La estrategia comercial es dedicar un alto esfuerzo en mantener el prestigio, la reputación, la confianza y en cultivar las relaciones sociales incrementando el conocimiento como soporte clave de venta, realizar un negocio exitoso es el elemento esencial, ya que son los que dan más bagaje en capacidades y referencias, y suponen una potente palanca para el avance en el desarrollo del negocio. (Eguren Segurado, Palacios Fernández, \& Roux Martínez, 2010). Generar confianza es una capacidad que siempre debe estar presente ya que es una condición necesaria en la relación con el cliente. El artesano que consigue que el cliente confié en él se sitúa en el grupo de posibles seleccionados, y a partir de ahí compite presentando las capacidades técnicas para vender su producto o servicios. Dotarse de prestigio y establecer una afamada reputación, son habilidades que les proporcionan un renombre y les abre las puertas a la negociación con los clientes creando y manteniendo numerosas relaciones sociales son capacidades ineludibles para establecer una red de contactos extensa que les facilite el acceso a los futuros consumidores. Magnificar los éxitos y utilizar una cierta dosis de astucia (Ploetner, 2008) es una habilidad para transmitir con mayor intensidad la capacidad que tienen de solucionar problemas". 
Según Bracho (2013), asegura que la captación de un cliente comienza desde el primer momento que se tiene contacto cara a cara con él, bien sea porque llega a la empresa o porque un representante de ventas va a su negocio, oficina o lugar de trabajo, con el fin de aplicar una serie de acciones tales como determinar las necesidades, y estructurar un mensaje claro que permitan captar a ese interesado, es decir, que permita conseguir que ese comprador repita sus compras en el negocio artesanal con la suficiente regularidad como para considerarlo cliente. El segundo momento se genera, cuando se tienen contacto cara a cara y se transmite claramente lo que se desea comunicar a la persona, se produce un intercambio de ideas y se genera una asesoría integral al mismo. Luego de aplicar las acciones anteriores, se da paso al tercer momento cuando se evidencia y registra la repetición de compra por parte del cliente, lo cual da a entender que sus necesidades con el producto o servicio quedaron satisfechas, y el mismo obtuvo un beneficio deseado y esperado con su consumo. Y finalmente, el último momento se produce cuando las acciones a aplicar durante el proceso de recompra, son claras y puntualizadas, es decir, se le comunica paso a paso los procesos o procedimientos a seguir en cada momento".

\section{Desarrollo}

Análisis del mercado. El análisis de mercado dará sustento a la mercadotecnia y su preocupación estará centrada en conocer que quiere el mercado, como lo que quiere y si la empresa está en capacidad de cubrir dichos mercados, por lo tanto, el análisis de mercado es un proceso sistemático y objetivo que permite captar la información necesaria para diseñar las estrategias de negocio y evaluar el proyecto (Martinez, 2014).

Un mercado es el conjunto de todos los compradores reales y potenciales de un producto, estos compradores comparten una necesidad o deseo determinado que se puede satisfacer mediante intercambios y relaciones, así el tamaño de un mercado depende del número de personas que sientan la necesidad, cuentan con los recursos para hacer un intercambio, y están dispuestas a ofrecer dichos recursos a cambio de lo que desean las economías modernas operan con base en el principio de división del trabajo, según el cual cada persona se especializa en la producción de algo, recibe un pago, y compra lo que necesita con ese dinero, los productores acuden a los mercados de recursos (de materias primas, de mano de obra, de dinero), adquieren recursos, los convierten en bienes y servicios, y los venden a intermediarios, los cuales los venden a los 
consumidores. Los consumidores venden su mano de obra, por lo que reciben ingresos con los que pagan los bienes y servicios que compran (Bravo Oviedo \& Acosta Cayetano, 2015).

Captación de clientes. Es clave para crecer y sobrevivir en un mercado cada vez más cambiante, con una competencia mayor y más diversificada, con nuevas tendencias que marcan el destino y con clientes con más poder de decisión que nunca (Gonzalo de la Hoz, 2017). A continuación, se detallarán las estrategias para captar clientes dentro de la organización según (Contreras Rentería, 2016), menciona:

Definir el target: Éste es el primer paso que debemos dar si queremos conocer cuáles son realmente nuestros clientes potenciales, llevando a cabo un concienzudo estudio de mercado. Por medio de este estudio de mercado el artesano puede conocer sus futuros clientes los mismo que van hacer que sus negocios tengan éxitos ya que contarían con estos consumidores potenciales.

Segmentar el mercado: Una vez que conocemos cuáles son nuestros clientes, podemos segmentar el mercado para así centrar nuestras energías y recursos con acciones comerciales y de marketing hacia el segmento adecuado. La segmentación de mercado es muy importante para los negocios manufactureros ya que una vez que conocemos a los clientes es necesario identificarlos en grupos de consumidores, es decir, conocer sus diferentes necesidades, características y comportamientos lo mismos que requieren un marketing adecuado.

Escuchar al cliente: Según el autor se refiere que puede parecer una obviedad, pero dado que el producto o servicio que ofrecemos tiene que satisfacer una necesidad, es vital que escuchemos qué es lo que el cliente desea y busca para así cubrir este deseo. Lo más importante del negocio artesanal es llegar al cliente y por ende conocer sus gustos y necesidades dando la mayor importancia en la comunicación.

Desarrollar el área comercial: Es nuestro principal instrumento para vender nuestro producto o servicio, y una vez que hemos identificado cuál es nuestro tipo de Cliente, es importante capacitar a los profesionales que van a poner en valor nuestro producto o servicio. El área comercial requiere de capacitación para que se identifiquen con los productos y servicios manufacturados que conozcan todas las bondades que poseen el producto y así poder ofrecer a nuestros clientes un producto confiable y con calidad. 
Escoger la vía adecuada: Para dar a conocer las bondades de nuestro producto o servicio, es importante diseñar acciones publicitarias y de marketing acordes con el cliente que pretendemos captar. Tendremos que identificar si es mejor realizar acciones de patrocinio, aprovechar las redes sociales o publicitarse en la prensa escrita o en la radio. Para llegar a nuestros consumidores tenemos que tener una buena estrategia publicitaria que puedan entrar en la psicología del cliente, es decir el marketing más adecuado donde se demuestre que el producto es excelente y satisfactorio, ejemplo; redes sociales que son gratis y hacen buena publicidad mediante videos viralizados.

No olvidar a la competencia: Es necesario estar en permanente contacto con la competencia, con sus acciones y sus estrategias de marketing y venta. Además, qué es lo que están ofreciendo, qué nuevas ventajas ofrecen sus productos o servicios, etc. La competencia también es parte de nuestro negocio ya que tenemos que conocer las ofertas que ellos dan especialmente en temporadas de consumo masivo ejemplo navidad, año nuevo, carnaval, etc.

Ofrezca un valor diferencial: Teniendo en cuenta lo que la competencia está ofreciendo, tiene que ser una prioridad para nosotros el buscar y llegar a ofrecer, con nuestro producto o servicio, un valor diferencial respecto al resto de competidores del mercado.

Podemos analizar el mercado local y verificar los costos de productos similares con las cuales nuestros productos artesanales están compitiendo, en este aspecto podríamos reducir económicamente los gastos de producción para poderlos vender más barato al alcance del mercado. Al producir los mismo bienes y servicio a un precio más bajo que la competencia, el gremio artesanal puede obtener beneficios adicionales y seguir trayendo clientes con precios más bajos.

\section{Capacitaciones en ventas}

Se ha discutido por largo tiempo, si la habilidad de vender es un arte o una ciencia, si es algo innato o algo que puede ser enseñado o aprendido, dentro de las funciones o actividades que se tienen en una empresa, la formación de cuadros de excelencia para el logro de objetivos es una parte vital. Se debe decidir en qué rubros se formará al personal, partiendo de las características formativas y experiencias previas, es decir, debe hacerse un Diagnóstico de Necesidades de Capacitación, la necesidad de formar en cinco rubros específicos: 1) Habilidades comunicativas, 
aquí deben integrarse aquellas habilidades que se enseñan en Programación Neurolingüística, a fin de que el vendedor sepa interpretar las pautas psicológicas envueltas en los procesos comunicativos con los compradores. 2)Tolerancia a la frustración, para que el vendedor sepa manejar los triunfos y derrotas de modo que cada una de sus experiencias, buenas o malas, le permita incrementar su marco de referencia y tome esas experiencias para el análisis de mejores prácticas laborales.3)Capacidad de Organización, enseñar a la persona a ser organizada, a manejo de tiempo y agenda, a la organización de sus archivos y llenado de reportes.4)Creatividad, desarrollarle la habilidad de pensamiento lateral, invitándolo a que innove y encuentre nuevas formas de hacer las cosas.5)Liderazgo, convirtiéndole en guía, asesor y gerente de sus actividades personales y de las de los equipos de trabajo en que participa, de manera que vea su trabajo como un negocio personal (Juárez Martínez, 2010).

Asistencia Técnica. -Según (Foundation Center, 2017), define en forma global como servicios profesionales o especializados que sirven de apoyo para las organizaciones sociales que carecen de dichas capacidades en lo cual los programas de asistencia técnica ayudan a la organización a marchar más eficientemente. Servicios según (Lozano Rojo, 2001) lo define como "actividades basadas en la aportación de trabajo, es decir, en que unos recursos que cuentan con los conocimientos o capacitaciones adecuadas dedican un tiempo para aplicar dichos conocimientos a un fin".

\section{Comercio artesanal}

La artesanía, como parte de las industrias culturales, es un factor importante a considerar en las economías modernas; ya que no solo contribuyen en el crecimiento económico de los países, generando empleo e ingresos, sino que también ayuda a transmitir y mantener las raíces culturales, identidad de las naciones, la artesanía está resurgiendo paralelamente al declive de la artesanía folclórica, el mundo del diseño, está redescubriendo, desde diferentes perspectivas, los valores emocionales, sensoriales y sociales contenidos en el saber artesanal. Por ello están provocando la diversificación de demanda artesanal en diferentes mercados, utilizando diferentes canales comerciales y estrategias de comunicación diferenciada (Navarro Hoyos, 2016). 
Estrategias comerciales. Consisten en acciones que se llevan a cabo para alcanzar determinados objetivos relacionados con el marketing, tales como dar a conocer un nuevo producto, aumentar las ventas o lograr una mayor participación en el mercado. Para formular o diseñar estrategias comerciales, además de tomar en cuenta nuestros objetivos, recursos y capacidad, debemos previamente analizar nuestro público objetivo, de tal manera que en base a dicho análisis podamos, por ejemplo, diseñar estrategias que nos permitan satisfacer sus necesidades o deseos, o que tomen en cuenta sus hábitos o costumbres. Otro punto importante, además de analizar el público objetivo, también debemos previamente analizar la competencia, de tal manera que en base a dicho análisis, podamos diseñar estrategias que nos permita aprovechar sus debilidades, o que se basen en las estrategias que estén utilizando y que mejores resultados les estén dando, es decir, aplicar el benchmarking (Yanchapaxy Jacho, 2015).

Estrategias publicitarias. Se define como una actividad que desarrolla una empresa para comunicar algún mensaje respecto de su producto o servicio con el propósito fundamental de incrementar sus ventas usando como insumo un medio de comunicación, la publicidad puede comunicar innovaciones en el producto o servicio, disminuciones de precio o promociones. Existen al menos 3 puntos de vista al momento de clasificar las estrategias publicitarias: la informativa, la persuasiva y la complementaria. Por el lado de la demanda, la publicidad persuasiva puede servir para alterar los gustos y preferencias de los consumidores creando una diferenciación de producto y lealtad a la marca, que conducirá a que la demanda del producto de la empresa se haga más inelástica. Por el lado de la oferta, este tipo de publicidad puede convertirse en una barrera a la entrada, es decir, puede tener efectos anticompetitivos. Este tipo de publicidad no aporta un valor real a los consumidores, pero sí induce una diferenciación artificial de producto. Por su parte, la publicidad de tipo informativa surge como respuesta endógena al mercado, pues para este punto de vista existen muchos mercados que están caracterizados por tener consumidores poco informados, lo que puede llevar a ineficiencias de mercado (Cruz Rodríguez, 2014). Es por esto que el éxito de las estrategias publicitarias depende de factores como: 1) Un análisis acertado de recursos, capacidades, fortalezas, debilidades, amenazas y oportunidades, 2) evaluación de los competidores, 3) evolución del entorno y su relación con las previsiones planes y cálculos de la empresa, y 4) las acciones de la competencia (Palamary D’Aguillo, 2012). 
Estudio de mercado. Consiste en una iniciativa empresarial con el fin de hacerse una idea sobre la viabilidad comercial de una actividad económica establecido ya que el estudio de mercado es un proceso que nos ayuda a recoger información y analizar datos, su uso tiene como objetivo ayudarnos a crear un plan de negocio, lanzar un nuevo producto o servicio, mejorar los existentes y a expandirse a nuevos mercados ya que puede usarse para determinar qué porcentaje de la población es receptiva a comprar nuestro producto basándonos en variables como el género, la edad, la ubicación o el nivel de ingresos, pueden ser dos clases: 1)Estudios cualitativos ,suelen ser útiles al principio del proyecto, cuando se sabe muy poco sobre el tema engloban entrevistas individuales y detalladas o debates con pequeños grupos, que permitan todas ellas analizar los puntos de vista y la actitud de la gente de forma informal., 2) Estudios cuantitativos, su objetivo es medir, numerar, gran parte de estos estudios pretenden establecer cuánta gente comprar un determinado producto, con qué frecuencia, se basan generalmente en muestras al azar y se pueden proyectar a una población más amplia por medio de las encuestas ( Dobón, 2014).

Gremios artesanales. Es una asociación sin fines de lucro de empresas artesanas y profesionales artesanos, entre sus fines se encuentra la defensa, tutela y custodia de la artesanía y sus oficios, la promoción y difusión del sector artesano y la formación específica (Gremio Artesanos org, n.d.). Se dedicaban a la enseñanza de sus labores, estas cuestiones hacen que los gremios sean considerados como el punto de partida hacia los sindicatos modernos (Pérez Porto \& Merino, 2009).

Artesano Calificado. Persona natural que domina la técnica de un arte u oficio, con conocimientos teóricos y prácticos, que ha obtenido el título y calificación correspondiente, conforme a las disposiciones legales y reglamentarias pertinentes y dirige personalmente un taller puesto al servicio público (Ley de Fomento Artesanal, 2008).

Artesano no Calificado. Persona natural que domina la técnica de un arte u oficio con pequeños negocios que cuentan con recursos económicos bajos y que no han obtenido el título y calificación correspondiente conforme a las disposiciones legales y reglamentarias pertinentes (Jaya, 2016). 
Mercado comercial. Refiere a cualquier signo que identifique a una actividad económica, a una empresa, o a un establecimiento mercantil. El nombre comercial puede consistir en la denominación social de la empresa, en su razón social u otra designación inscrita en un registro de personas o sociedades mercantiles. El nombre comercial es independiente de la razón social de las personas jurídicas, sin embargo, puede coexistir con ella o ser simultáneamente su razón social. Un comerciante puede utilizar más de un nombre comercial, es decir, identificar sus diferentes actividades empresariales con diversos nombres comerciales. El nombre comercial es independiente de la razón social de la persona jurídica, pudiendo coincidir con ella; es decir, un comerciante puede tener una razón social y un nombre comercial idéntico a ésta, o tener una razón social y uno o muchos nombres comerciales diferentes de ella, el nombre comercial puede ser múltiple, mientras que la razón o denominación social es única; es decir, un comerciante puede tener muchos nombres comerciales en el mercado comercial pero sólo una razón social (Rengifo García, 2017).

En el mercado Comercial artesanal está sujeta a la realidad del comercio en el que se mueve, como en cualquier otra empresa, en la actividad artesana hay que realizar toda una serie de tareas, diseñar o ajustarse a un diseño, adquirir materias primas, realizar el objeto y vender, los aspectos que hacen singular al mercado artesanal suelen ser, su tamaño minúsculo y la relación emocional entre el artesano y el producto por él elaborado. (Industrias Artesanales, 2003).

Producto manufacturado. En todo mercado existen diversos tipos de productos, los denominados productos manufacturados son aquellos artículos o bienes de valor agregado que se obtienen tras un proceso en el que intervienen tanto la mano de obra de los trabajadores como la asistencia de determinada maquinaria, las materias primas y ciertos recursos naturales o minerales son el principal insumo de los productos manufacturados que encontramos a diario en el mercado, sin embargo, esto no quiere decir que sea una categoría uniforme. Al contrario, se trata de un grupo diverso, amplio y a veces complejo en el que se incluyen diferentes tipos de artículos con procesos de elaboración de diversa índole (OBS Business School, n.d.). Los productos manufacturados se pueden agrupar en: 
- $\quad$ Bienes de consumo, manufacturados para ser consumidos por el cliente final.

- $\quad$ Bienes de capital, productos manufacturados destinados a ser empleados en la fabricación de otros bienes o prestación de servicios.

- $\quad$ Materiales, componentes y suministros. Empleados en los tipos anteriores, normalmente tratamiento de materias primas para su uso industrial, piezas y repuestos, (Enciclopedia, n.d.).

Técnicas de ventas. Es la ciencia de interpretar características del producto o servicio, en términos de satisfacción del consumidor, para actuar después mediante técnicas adecuadas sobre el convencimiento de sus beneficios y la persuasión de la conveniencia de su posesión o disfrute inmediatos, la principales técnicas fundamentales son, antes de convencer este convencido, diga siempre la verdad, dramatice la oferta, limite la atención a un solo tema, diga siempre el porqué de cada cosa y dé preferencia a la argumentación visual (Llamas, 2004). Por otra parte, De La Parra \& Madero (2003), menciona que esta técnica es aquella persona que ejerce la ciencia y el arte de la venta, interpretando los requerimientos de los prospectos, y aplicando su cultura general, psicología, conocimientos sobre los estilos, gustos, preferencias y sus conocimientos técnicos permanentemente actualizados, para satisfacer las necesidades, deseos, preferencias y temores de los clientes y consumidores, con fines de bien común. El primer paso consiste en que el vendedor capte la atención del cliente, si el cliente no está interesado en lo que va a escuchar, la venta estará perdida. La importancia de esta fase es crucial para el buen desarrollo de la venta. (Ortega Valencia, 2013).

\section{Metodología}

Para este trabajo de investigación se empleó la investigación documental, que según Fidias G. Arias (2006), es un proceso basado en la búsqueda, recuperación, análisis, crítica e interpretación de datos secundarios, es decir, los obtenidos y registrados por otros investigadores en fuentes documentales: impresas, audiovisuales o electrónicas. Como en toda investigación, el propósito de este diseño es el aporte de nuevos conocimientos. Para ello se realizó un estudio bibliográfico de las acciones que permiten que el artesano tenga un lineamiento en la investigación de mercado para la captación de clientes utilizando estrategias comerciales que le permitan llegar al público con las artesanías, direccionando en buscar las razones primordiales de las dificultades orientados a la realidad. Al mismo tiempo se evaluó la calidad de los productos artesanales basándose en los 
conocimientos y experiencias, además el tipo de servicios que brinda este gremio artesanal del Cantón Naranjito. La población la constituyeron 164 artesanos de los cuales 45 son calificados.

\section{Análisis de la información.}

El gremio de artesanos ha logrado alcanzar un reconocimiento social por el rol que desempeña en sus actividades dentro de la economía, las artesanías pueden ser apreciadas en todas las regiones del país, ya que se cuenta con materia prima única que identifica a cada región. Cada artesanía es auténtica, prevaleciendo siempre la originalidad de sus piezas, los materiales con los que se elaboran y las técnicas desarrolladas por la experiencia de generaciones, por lo que la competitividad en este arte depende del artesano que pone mística, dedicación y sello propio en cada artesanía que la distingue no solo en las distintas ciudades sino regiones y comunas (Dirección de Inteligencia Comercial e Inversiones, 2013).

El sector manufacturero en el Cantón Naranjito se desarrolla mediante talleres pequeños algunos de ellos con maquinarias o manualmente se realiza la producción y se lleva a cabo en primera escala y por lo tanto su circulación tiende a ser limitada. Podemos mencionar talleres bloqueras donde se construyen floreros, figuras de animales que son adorno decorativo que se utilizan en las casas, también contamos con mecánicos, gabinetes de bellezas, bisuterías, talleres de soldaduras, de torno, carpintería de aluminio y madera, sastrerías, panaderías, zapaterías, electricistas, etc. El comercio interno se lo realiza en algunos casos en los propios talleres de producción y en otros casos se lleva a los lugares de consumo, es decir, a la parte céntrica del Cantón Naranjito donde se encuentran los locales comérciales, este movimiento de producción y venta se lo realiza mediante transporte terrestre dando lugar a fuentes de empleo para muchos jóvenes, y al mismo tiempo dinamizan la activad comercial del cantón.

Uno de los principales problemas de la artesanía es la competencia con los productos procedentes de procesos industriales de bajo costo de otras ciudades, con apariencia similar a los productos artesanales del Cantón Naranjito, pero con menor precio y calidad, otra dificultad para los artesanos es la forma de comercializar sus productos, ya que es una característica de la artesanía, que se realiza en talleres individuales o de pocas personas, con poca capacidad para llegar al mercado, para garantizar la comercialización (Sierralta, 2014). 
Para lograr vencer estos obstáculos de competencia se utilizarán técnicas de ventas como:

Método de Preferencia del costo. - Se analiza el mercado local y verifican los costos de productos similares con las cuales los productos artesanales están compitiendo, en este aspecto se podrían reducir económicamente los gastos de producción para poderlos vender más barato al alcance del mercado. Al producir los mismos bienes y servicios a un precio más bajo que la competencia, el gremio artesanal puede obtener beneficios adicionales y seguir trayendo clientes con precios más bajos.

Ventajas de diferenciación de productos. - Este aspecto se considerará como una técnica de venta al utilizar nuevas etiquetas que realcen las características del producto con un mensaje que impacte al consumidor y lo induzca al consumo del producto.

Método de nuevas ofertas. - Esta técnica implica que el vendedor va a ofertar su producto por pronto pago con un descuento del $50 \%$ en el precio del producto y que además esta promoción es por corto tiempo ejemplo duración 10 días, induciendo al cliente a la compra del producto artesano.

Escuchar con atención al cliente. - Unos de las técnicas principales de una empresa o negocio para vender sus productos es escuchar con atención las necesidades que tienen el cliente al buscar un producto, debemos verificar exactamente que busca el cliente si el producto que se le ofrece cumple las expectativas para sus necesidades de su familia y de él.

Al describir estas técnicas de venta el sector artesanal trabajará con más confianza en su potencial de producción y servicios aplicándolos en el mercado local.

Las estrategias comerciales que se pueden utilizar para la captación de clientes en el gremio artesanal del Cantón Naranjito serían los siguientes:

Estrategia competitiva del producto y servicio. - Un producto es un artículo que va ser utilizado por el cliente el mismo que necesita satisfacer las necesidades del comprador se puede mencionar que hay muchas cosas que llaman la atención, y que van a servir de ayuda y satisfacción del deseo del comprador por ende el producto tiene que ser de calidad para que sea competitivo en el mercado. 
Estrategia de liderazgo en costos. - Ante la presencia de una barrera de entrada de productos o servicios de la competencia por costos más baratos, surge la gran pregunta para los artesanos ¿Tenemos un rival que es la competencia, podremos seguir con los costos iguales o por debajo de la competencia? Si no lo puede hacer este negocio artesanal será barrido por lo precios de la competencia, pero si utiliza una buena estrategia en la producción de costos lo podemos abaratar, pero sin descuidar la calidad del producto o servicio.

Estrategia de marketing y publicidad. - El producto o servicio artesanal deberá ser conocido en el mercado sus cualidades y ventajas los mismo que deben penetrar en la mente del comprador para ello se puede utilizar varias opciones publicitarias tales como folletos, revistas, radio, televisión, carteles en los locales y vías públicas, redes sociales, tarjetas de presentación y periódico.

Estrategia de canales de venta. - Debemos buscar los medios de cómo llegar a los clientes estableciendo canales de venta, es decir, focalizando donde existen más consumidores, pudiendo llegar a ellos con una excelente publicidad, dando un mejor asesoramiento del producto y servicio, es decir, donde podemos obtener mayor imagen y valor de lo manufacturado.

Estrategia de desarrollo del mercado. - En el mercado del Cantón Naranjito la estrategia es incrementar las ventas o servicios en la localidad, pero se buscará vender en otros mercados comerciales en utilizando nuevos segmentos de usuarios:

- $\quad$ Vender productos y servicio a otros grupos o sectores diferentes.

- $\quad$ Satisfacer los requerimientos de los nuevos clientes.

- $\quad$ Lograr mostrar la marca del producto en otras localidades.

Al describir todas estas estrategias comerciales el sector artesanal estará preparado para captar clientes en el mercado local. Es importante mencionar en las estrategias comerciales la credibilidad y tangibilidad en el momento de trabajar con los clientes porque esto producirá seguridad y seriedad en la obtención de los productos manufacturados considerando que el cliente debe recibir una excelente atención para lograr que el mensaje que lleva el producto o servicio trascienda multiplicando su utilización ya que la calidad del producto complazca sus necesidades. 
Según un artículo publicado en diario el telégrafo, Gabriela Samaniego (2017), comerciantes de artesanías, destacan que el municipio debe hacer más promoción de centros comerciales artesanales y en el diario el universo, Javier González (2018) menciona que fortalecer los emprendimientos artesanales mediantes estrategia publicitaria es una herramienta práctica de marketing y comercialización para plazas artesanales, permitirá a los emprendedores mejorar la calidad de los servicios y productos ofertados a los consumidores.

La publicidad puede ayudar a incrementar las ventas artesanales si se hace sensatamente y bien. Hacerlo sensatamente quiere decir apuntarle al mercado; hacerlo bien quiere decir poner avisos que vendan. La publicidad es un medio para transmitir un mensaje, y es donde y como lo transmite lo que hará de la publicidad una fuerza de ventas positiva para el artesano, como estrategias publicitarias:

Existen diversas formas de llegar al cliente final, por periódicos, a través de redes sociales, mediante propaganda de televisión, radio y por medio de la venta directa. A medida que un negocio artesanal evoluciona y crece todas estas formas se pueden ir ensayando hasta encontrar la que más conviene. La forma más eficaz de llegar a los clientes potenciales, al menos en la etapa inicial, es a través del contacto personal, entrevistando al mayor número posible de compradores potenciales para persuadirlos de que compren el producto o servicio. Las transacciones del negocio artesanal se efectúan persona a persona por lo tanto, el éxito de la venta dependerá de la empatía que desarrolle con los clientes potenciales para lograr una relación armónica de beneficio mutuo desarrollando en la mente del consumidor una oportunidad excepcional de que el cliente comunica los beneficio que tuvo a otros futuros clientes haciendo una cadena de comunicación captando de manera efectiva y duraderas a mas consumidores, la oportunidad de desarrollar estas relaciones, en un mundo cada día más, representa una verdadera ventaja competitiva, que debe ser capitalizada con inteligencia.

Mediante el análisis del mercado, consiste en averiguar quiénes son y dónde están esos compradores, la investigación del mercado es simplemente el proceso de reunir información y analizarla, la información forma entonces la base para la toma correcta de decisiones. Ayudará al artesano a determinar con precisión la publicidad, a desarrollar un proyecto de marketing y a 
vender su producto. Saber que las decisiones están respaldadas por el conocimiento y el análisis no solamente minimiza el riesgo, sino que fortalece la confianza.

De acuerdo al Gad Municipal del Cantón Naranjito las estadísticas que maneja el departamento de avalúos y catastro, los artesanos son un total de 164 negocios que poseen, siendo los calificados un total de 46 artesanos, considerando que 118 no están registrados en el gremio artesanal del Cantón Naranjito. (Ver Tabla 1 y Tabla 2)

Podemos mencionar que solo el $28.05 \%$ están registrados en el gremio artesanal los cual nos indica que es una minoría que goza de los derechos que corresponden a dicho gremio ejemplo en lo laboral exoneración de pago de utilidades y bonificación complementaria a los operarios, en lo social acceso a las prestaciones del seguro y créditos preferenciales por medio del banco nacional de fomento, en tributos facturación con tarifa $0 \%$ (I.V.A.) y exoneración de impuesto a la exportación (Heraldo, 2014).(Ver Tabla 1)

El 71.95\% que son los artesanos no calificados no le ha dado importancia en formar parte del gremio artesanal del Cantón Naranjito debido al desconocimiento de los beneficios que pudieran percibir. (Ver Tabla 2)

De acuerdo a la tabla de la asociación artesanal el taller de mecánica automotriz tiene un porcentaje alto $6.10 \%$ que brinda un servicio profesional analítico, critico, reflexivo e eficiente en cuanto a la reparación de vehículos relevando los valores de honradez ética y responsabilidad. Este profesional está capacitado para resolver problemas relacionados con la reparación de motores de diésel o gasolina con una orientación teórica y práctica dirigidos al mantenimiento de motores de inyección, carburadores y reconstrucción de vehículos en general. Su estudio y capacitación se lo dio mediante el gremio de artesanos, estos talleres cuentan con 4 operarios que están al mando del profesional mencionado (Instituto Tecnológico Superior Oriente, n.d.). (Ver Tabla 1)

De acuerdo a la tabla de la asociación artesanal el taller de soldadura tiene un porcentaje 4.27\%, en los talleres de soldadura del Cantón Naranjito se pude mencionar que en este campo industrial los trabajos se realizan de calidad con un equipo de humano capacitado que garantiza la satisfacción de los clientes en estos talleres se realizan trabajos para maquinarias en la 
construcción de piñones, ejes, pistones, bridas, bocines, cilindros, etc., estos talleres cuentan con 3 operario (Escuela Politécnica Nacional, 2012). (Ver Tabla 1)

De acuerdo a la tabla de la asociación artesanal el taller electrónico tiene un porcentaje 3.66\% el profesional en esta rama da un servicio rápido y de calidad son especialistas en arreglos eléctrico, por ejemplo; en coches, máquinas de corrientes continua, motores de media y baja tensión, moto bomba, rebobinajes de alternadores, motores de arranque, etc. Este técnico tiene centrado su negocio con 2 operarios que brindan reparaciones, instalaciones y mantenimientos electrónicos (Taller Eléctrico González, n.d.). (Ver Tabla 1)

Los gabinetes de belleza también forman parte de los servicios manufacturados que brindan los negocios en el Cantón Naranjito, un centro de belleza se ofrece servicios orientados hacia el embellecimiento tanto del cabello o de la piel, manos y pies. El profesional de esta rama es un experto y calificado que conoce de la estética por lo tanto puede ser unisex que ofrece trabajo de cortes de pelos, aplicaciones de tintes, luces, reflejos, rizado, alisado, tratamientos o mascarillas, por lo general un gabinete de belleza ofrece trabajo a 2 operarios (Guías prácticas, 2015).

Los talleres de carpintería de aluminio también forman parte del sector manufacturero del Cantón Naranjito con el $3.05 \%$, en estos talleres se realizan corte, armado y montaje de ventanas de vidrio, ventanas corredizas, ventanas oscilo batientes, ventanas fijas, mamparas, puertas de aluminio, vitrinas aluminio y vidrio. El técnico en esta rama trabaja con tres operarios en su taller (Centro Nacional de Educación a Distancia, 2018). (Ver Tabla1)

Como podemos observar en el Cantón Naranjito el sector manufacturero es de vital importancia para el movimiento de la economía local, siendo su fortaleza los distintos talleres de manufactura que dan trabajo día a día a los jóvenes del Cantón Naranjito, y al mismo tiempo se está capacitando al operario en una profesión que en el futuro serán los nuevos maestros de estas ramas. 
Tabla 1: segmentación y datos de los artesanos

\begin{tabular}{|c|c|c|}
\hline Asociación Artesanal & $\begin{array}{c}\text { Cantidad de Artesanos } \\
\text { Calificados }\end{array}$ & $\begin{array}{l}\text { \% Representativo de } \\
\text { Artesanos Calificados }\end{array}$ \\
\hline Taller de Albañilería & 1 & $0.61 \%$ \\
\hline $\begin{array}{c}\text { Taller de Mecánica } \\
\text { automotriz }\end{array}$ & 10 & $6.10 \%$ \\
\hline Taller de Soldadura & 7 & $4.27 \%$ \\
\hline Taller Electrónicos & 6 & $3.66 \%$ \\
\hline Gabinetes de Belleza & 4 & $2.44 \%$ \\
\hline Taller de Tapicería & 1 & $0.61 \%$ \\
\hline Taller de Fibra de Vidrio & 1 & $0.61 \%$ \\
\hline $\begin{array}{l}\text { Taller de Mecánica } \\
\text { Industrial }\end{array}$ & 1 & $0.61 \%$ \\
\hline Taller de Refrigeración & 2 & $1.22 \%$ \\
\hline Taller de Motos & 1 & $0.61 \%$ \\
\hline $\begin{array}{c}\text { Taller de Carpintería de } \\
\text { Aluminio }\end{array}$ & 5 & $3.05 \%$ \\
\hline Taller de Ebanistería & 4 & $2.44 \%$ \\
\hline Floristería & 0 & - \\
\hline Panadería & 0 & - \\
\hline Taller de Sastrerías & 3 & $1.83 \%$ \\
\hline Total & 46 & $28.05 \%$ \\
\hline
\end{tabular}

Fuente: GAD. Municipal del Cantón Naranjito (2017).

ELABORADO POR: los autores.

Tabla 2: segmentación y datos de los artesanos

\begin{tabular}{|c|c|c|c|c|}
\hline $\begin{array}{c}\text { Asociación } \\
\text { Artesanal }\end{array}$ & $\begin{array}{c}\text { Cantidad de } \\
\text { Artesanos no } \\
\text { Calificados }\end{array}$ & $\begin{array}{c}\text { \%Representativo } \\
\text { de Artesanos no } \\
\text { Calificado }\end{array}$ & $\begin{array}{c}\text { Total, de } \\
\text { Artesanos }\end{array}$ & $\begin{array}{c}\text { \%Representativo } \\
\text { del Total de } \\
\text { Artesanos }\end{array}$ \\
\hline $\begin{array}{c}\text { Taller de } \\
\text { Albañilería }\end{array}$ & 0 & - & 1 & $0,61 \%$ \\
\hline $\begin{array}{c}\text { Taller de } \\
\text { Mecánica } \\
\text { Automotriz }\end{array}$ & 9 & $5,49 \%$ & 19 & $11,59 \%$ \\
\hline $\begin{array}{c}\text { Taller de } \\
\text { Soldadura }\end{array}$ & 8 & $4,88 \%$ & 15 & $9,15 \%$ \\
\hline $\begin{array}{c}\text { Taller } \\
\text { Electrónicos }\end{array}$ & 0 & - & 6 & $3,66 \%$ \\
\hline
\end{tabular}




\begin{tabular}{|c|c|c|c|c|}
\hline $\begin{array}{c}\text { Gabinetes de } \\
\text { Belleza }\end{array}$ & 27 & $16,46 \%$ & 31 & $18,90 \%$ \\
\hline $\begin{array}{l}\text { Taller de } \\
\text { Tapicería }\end{array}$ & 3 & $1,83 \%$ & 4 & $2,44 \%$ \\
\hline $\begin{array}{c}\text { Taller de Fibra } \\
\text { de Vidrio }\end{array}$ & 0 & - & 1 & $0,61 \%$ \\
\hline $\begin{array}{l}\text { Taller de } \\
\text { Mecánica } \\
\text { Industrial }\end{array}$ & 0 & - & 1 & $0,61 \%$ \\
\hline $\begin{array}{c}\text { Taller de } \\
\text { Refrigeración }\end{array}$ & 1 & $0,61 \%$ & 3 & $1,83 \%$ \\
\hline $\begin{array}{l}\text { Taller de } \\
\text { Motos }\end{array}$ & 20 & $12,20 \%$ & 21 & $12,80 \%$ \\
\hline $\begin{array}{c}\text { Taller de } \\
\text { Carpintería de } \\
\text { Aluminio }\end{array}$ & 5 & $3,05 \%$ & 10 & $6,10 \%$ \\
\hline $\begin{array}{c}\text { Taller de } \\
\text { Ebanistería }\end{array}$ & 1 & $0,61 \%$ & 5 & $3,05 \%$ \\
\hline Floristería & 4 & $2,44 \%$ & 4 & $2,44 \%$ \\
\hline Panadería & 23 & $14,02 \%$ & 23 & $14,02 \%$ \\
\hline $\begin{array}{l}\text { Taller de } \\
\text { Sastrerías }\end{array}$ & 17 & $10,37 \%$ & 20 & $12,20 \%$ \\
\hline Total & 118 & $71,95 \%$ & 164 & $100,00 \%$ \\
\hline
\end{tabular}

Fuente: GAD. Municipal del Cantón Naranjito (2017).

La captación de clientes en el trabajo artesanal no solo fortalece y consolida las identidades locales y regionales, sino que es un gran dinamizador de la economía, un sector fundamental que lamentablemente no siempre ha sido comprendido ni ha recibido el trato desde el estado, en la Asamblea Nacional se tramita una nueva ley que debe garantizar los derechos adquiridos en años de lucha y trabajo fomentando el desarrollo del sector artesanal con mecanismo de acceso a crédito, con redes de distribución y comercialización que generen un precio justo para nuestros artesanos (El Telégrafo \& Salgado Jacome, 2017). 
Según el estudio del Colegio de Profesionales de Mercadotecnia del Ecuador, realizando en abril del 2009 en convenio con la Cámara Artesanal del Guayas, el 95.16\% de los artesanos en el Guayas tienes unidades económicas familiares que subsisten de la actividad manual; el estudio además revela que la actividad de los artesanos es frágil debido a las dificultades socio económicas, tecnológicas para su desarrollo; por otro lado, pese a la diversidad, los artesanos son generadores de fuentes de trabajo, es un de las razones de por qué, el sector artesanal es considerado como un segmento estratégico para la dinámica socio económica local y nacional (Ramos Herán \& Ancayay Leal, 2013). La capacitación en ventas es esencial para el éxito de los negocios en los artesanos, cuándo un vendedor artesanal se coloca frente a un cliente potencial, estar preparado con conocimiento del producto, precios y una presentación puede marcar la diferencia en las ventas. Por esta razón, el proceso de capacitación de ventas es un aspecto importante en el proceso de captación de clientes.

\section{Conclusiones}

Se conoció la realidad del sector manufacturero del Cantón Naranjito en base al análisis de las estrategias comerciales que aplican en sus negocios, su crecimiento técnico y práctico les ha permitido brindar un servicio de calidad.

Se puede observar que en el Cantón Naranjito hay varios negocios que pertenecen al sector manufactureros pero las estrategias comerciales que han empleados no les ha permitido una captación eficiente de cliente lo cual ha disminuido las ventas y por ende su permanencia en el mercado local.

El sector manufacturero del Cantón Naranjito al innovar sus productos y servicios que van a ser utilizado por el cliente el mismo que necesita satisfacer las necesidades del comprador se puede mencionar que hay muchas cosas que llaman la atención, y que van a servir de ayuda y satisfacción del deseo del comprador, por lo cual se debe inclinar a los gustos de los clientes.

El gremio artesanal del Cantón Naranjito no aplica técnicas de ventas lo cual afecta al nivel de clientes, aplicando las debidas técnicas de ventas por ejemplo escuchar con atención al cliente al buscar un producto se debe verificar exactamente que busca el cliente si el producto que se le ofrece cumple las expectativas para sus necesidades de su familia y de él, esto es una motivación y estimulo que beneficiara a los negocios del sector manufacturero del Cantón Naranjito. 
En el sector manufacturero del Cantón Naranjito no apunta al mercado con una buena publicidad, existen diversas formas de llegar al cliente final: por periódicos, a través de redes sociales, mediante propaganda de televisión, radio y por medio de la venta directa, si lo hiciera bien transmitiera el mensaje lo que hará que las ventas se incrementen positivamente.

El plan de capacitación de ventas en el sector manufacturero es un aspecto importante en la captación del cliente, podemos decir que el conocimiento del producto es importante para su presentación, también la excelencia en el servicio al cliente, beneficiara el incremento de las ventas este plan de capacitación deberá ser monitoreado el mismo que se debe realizar un seguimiento para verificar el impacto que ha logrado en el incremento de la productividad y de las ventas.

\section{Referencias Bibliográficas}

Dobón, M. (2014). Que es un estudio de mercado. Recuperado de Gestión org: https://www.gestion.org/economia-empresa/48967/que-es-un-estudio-de-mercado/

Gremio Artesanos org. (s.f.). El Gremio de artesanías. Recuperado el 16 de Enero de 2018, de http://www.gremioartesanos.org

Samaniego, G. (20 de abril de 2017). El mercado artesanal del centro tiene poca venta. Obtenido de Diario el Telégrafo: Recuperado de http://www.eltelegrafo.com.ec/noticias/guayaquil/10/elmercado-artesanal-del-centro-tiene-poca-venta

Arias, F. (2006). El proyecto de investigación. Caracas -Venezuela: Episteme.

Bracho Luzardo, Y. C. (2013). Estrategias Promocionales Para la captación de Clientes en el área de repuestos y servicios del sector automotriz en el municipio Maracaibo. Maestría en Administración de Empresas. Universidad Rafael Urdaneta, 66-67.

Bravo Oviedo, J. N., \& Acosta Cayetano, N. D. (Marzo de 2015). Análisis de la problemática del mercado de las pymes del cantón milagro. Obtenido de Facultad de Ciencias Administrativas y Comerciales, Unemi: Recuperado de http://repositorio.unemi.edu.ec/xmlui/handle/123456789/2674 
Centro Nacional de Educación a Distancia. (2018). Curso de carpintería de aluminio. Obtenido de Objetivos: Recuperado de: http://cenedi.com/curso-de-carpinteria-de-aluminio

Contreras Rentería, D. (abril de 2016). Estrategias de marketing y la captación de clientes en la pañalera pototin del cantón Naranjito 2016 - 2017. Obtenido de Facultad Ciencias Administrativas y Comerciales, Universidad Estatal de Milagro: Recuperado de http://repositorio.unemi.edu.ec/xmlui/handle/123456789/2825

Cruz Rodríguez, I. J. (11 de marzo de 2014). Economías de escala publicitarias en grandes empresas en México. Obtenido de Facultad de Estudios Superiores Acatlán, Universidad Nacional Autónoma de México: Recuperado de http://www.scielo.org.co/scielo.php?script=sci_arttext\&pid=S0123-59232014000100002

De La Parra, E., \& Madero, M. (2003). Estrategias de ventas y negociación. Obtenido de Panorama Editorial: Recuperado de xhttps://books.google.es/books?hl=es\&lr=\&id=HGpXazBqgh0C\&oi=fnd\&pg=PA11\&dq=tecnic as + de+ventas\&ots=71avUHs_YR\&sig=6WZReKTZZcu_0rMujHNYdiIanM\#v=onepage \&q=tecnicas $\% 20 d e \% 20$ ventas $\& \mathrm{f}=$ false

Dirección de Inteligencia Comercial e Inversiones. (5 de noviembre de 2013). Análisis del sector artesanías. Obtenido de Características del sector y Recuperado de https://www.proecuador.gob.ec/pubs/analisis-sector-de-artesanias-2013/

Eguren Segurado, S., Palacios Fernández, M., \& Roux Martínez, F. (Octubre de 2010). Estudio sobre las estrategias comerciales de las empresas consultoras. Obtenido de Habilidades y $\begin{array}{llll}\text { estrategias comerciales } & \text { y } & \text { Recuperado de }\end{array}$ https://www.researchgate.net/publication/228452123_Estudio_sobre_las_estrategias_comerciales _de_las_empresas_consultoras_para_la_captacion_de_clientes

El Telégrafo, \& Salgado Jacome, P. (10 de Noviembre de 2017). La fiesta de las artesanías. Captación de clientes en el trabajo artesanal. Obtenido de El Telégrafo y Recuperado de http://www.eltelegrafo.com.ec/noticias/columnistas/1/la-fiesta-de-las-artesanias

Escuela Politécnica Nacional. (2012). Metalmecánica. Obtenido de Actividades: http://www.epn.edu.ec/metalmecanica-san-bartolo/ 
Foundation Center. (2017)¿Qué es la asistencia técnica? Obtenido de GrantSpace y Recuperado de http://grantspace.org/tools/knowledge-base/preguntas-y-respuestas-en-espanol/gestion-yadministracion/asistencia-tecnica-technical-assistance

GAD MUNICIPAL DEL CANTÓN NARANJITO. (2017). Asociación Artesanal. Naranjito: Departamento de Avalúos y Catastro.

González, J. (13 de enero de 2018). Emprendimientos comunitarios en ruta se fortalecerán. Obtenido de Diario el Universo: Recuperado de https://www.eluniverso.com/noticias/2018/01/13/nota/6563259/emprendimientos-comunitariosruta-tren-se-fortaleceran

Gonzalo de la Hoz. (27 de junio de 2017). Captación de clientes, 15 estrategias para mejorar tus ventas. Obtenido de Fuerza Comercial Consultoría: Recuperado de http://www.fuerzacomercial.es/captacion-de-clientes-15-estrategias-para-mejorar-tus-ventas/

Guías prácticas. (28 de enero de 2015). Salón de belleza. Obtenido de Qué son los salones de belleza: Recuperado de http://www.guiaspracticas.com/peluqueria-y-estetica/salon-de-belleza

Heraldo. (30 de marzo de 2014). Ley de defensa del artesano y sus beneficios. Recuperado el 8 de enero de 2018, de Diario Independiente El Heraldo: http://elheraldo.com.ec/index.php?fecha=2014-03-30\&seccion=Ciudad\&noticia=38603

Industrias Artesanales. (Febrero de 2003). Obtenido de KULTURAREN EUSKAL PLANA PLAN VASCO DE CULTURA: Recuperado de http://www.euskadi.eus/contenidos/informacion/pv_artesania/es_6625/adjuntos/artesania_c.pdf IJaya, M. (31 de octubre de 2016). Los artesanos calificados y no calificados. Obtenido de Slideshare Universidad Nacional del Chimborazo: Recuperado de https://es.slideshare.net/melissajaya/los-artesanos-calificados-y-no-calificados

Juárez Martínez, G. D. (Noviembre de 2010). Capacitación de vendedores. Obtenido de Contribuciones a la Economía: Recuperado de http://www.eumed.net/ce/2010b/gdjm.htm 
Ley de Fomento Artesanal. (14 de mayo de 2008). Artesano maestro de taller. Obtenido de Ministerio de Industrias y Productividad: http://www.industrias.gob.ec/wpcontent/uploads/2015/04/A2-LEY-DE-FOMENTO-ARTESANAL.pdf

Llamas, J. (2004). Estructura científica de la venta: técnicas profesionales de ventas. México: Editorial Limusa.

Lozano Rojo, J. R. (2001). PV. Asistencia técnica de postventa: logística; organización y operación optima, subcontratación de servicios, legislación. España: FUND. CONFEMETAL.

Martinez, E. (7 de marzo de 2014). Análisis de mercado. Obtenido de slideshare: Recuperado de https://es.slideshare.net/elvismartinez14606/plan-de-marketing-revisado

Navarro Hoyos, S. (2 de julio de 2016). La artesanía como industria cultural: Desafíos y oportunidades. Obtenido de Pontificia Universidad Javeriana, Departamento de Diseño, Facultad de Arquitectura y Diseño, Bogotá D.C., Colombia, S.A: Recuperado de https://www.fessociologia.com/files/congress/12/papers/3519.pdf

OBS Business School. (s.f.). ¿Qué tipos de productos manufacturados existen? Recuperado el 16 de enero de 2018, de Tendencias \& Innovación: Recuperado de https://www.obsedu.com/int/blog-investigacion/operaciones/que-tipos-de-productos-manufacturados-existen

Ortega Valencia, A. G. (2013). Programa de capacitación sobre la técnica de ventas. Obregón, Sonora: Instituto Tecnológico de Sonora.

Palamary D’Aguillo, R. E. (10 de Enero de 2012). Formación de equipos de alto desempeño y estrategias gerenciales en proyectos de empresas publicitarias. Obtenido de Facultad de Arquitectura y Diseño de la Universidad del Zulia: Recuperado de http://www.sciencedirect.com/science/article/pii/S0123592312701948

Pérez Porto, J., \& Merino, M. (2009). Definición de gremio. Obtenido de Definición. Recuperado de https://definicion.de/gremio/

Ramos Herán, P. E., \& Ancayay Leal, D. E. (Septiembre de 2013). Análisis de los principales problemas que inciden en el desarrollo económico y competitivo del sector artesanal del Cantón 
Milagro, provincia del Guayas. Obtenido de Facultad Ciencias Administrativas y Comerciales, UNEMI: Recuperado de http://repositorio.unemi.edu.ec/handle/123456789/615

Rengifo García, E. (noviembre de 2017). El nombre comercial. Obtenido de Revista la Propiedad Inmaterial; Bogotá n. $\quad{ }^{\circ} 17 \quad$ - $\quad$ pp. $187 \quad$ - 203: Recuperado de https://search.proquest.com/docview/1462482858/89D79C01493B4078PQ/2?accountid=38773

Samaniego, G. (20 de abril de 2017). El mercado artesanal del centro tiene poca venta. Obtenido de Diario el Telégrafo: Recuperado de http://www.eltelegrafo.com.ec/noticias/guayaquil/10/elmercado-artesanal-del-centro-tiene-poca-venta

Sanchez de Puerta, P. C. (2014). Dirección y estrategias de ventas e intermediación comercial. Obtenido de IC Rditorial: de https://books.google.com.ec/books?id=4QDoDQAAQBAJ\&pg=PT150\&dq=ESTRATEGIAS + C OMERCIALES\&hl=es-

419\&sa $=$ X\&ved $=0$ ahUKEwiN6K718tzYAhWE7lMKHd_xAY8Q6AEIMTAC $\mathrm{v}=$ onepage $\& \mathrm{q}=\mathrm{E}$ STRATEGIAS\%20COMERCIALES\&f=false

Sierralta, M. (28 de mayo de 2014). ¿Qué es la artesanía? ¿A quién llamar artesanos? Recuperado el 8 de enero de 2018, de Revista Guioteca: Recuperado de https://www.guioteca.com/manualidades-y-artesania/que-es-la-artesania-a-quien-llamarartesanos-las-respuestas-para-no-confundirnos/

Taller Eléctrico González. (s.f.). Taller eléctrico en Telde, profesionalidad y seriedad. Recuperado el 23 de enero de 2018, de centro especializado: Recuperado de http://www.tallerelectricogonzalez.es/es/

Tapia, E. (25 de agosto de 2017). ¿Cómo obtener la calificación de artesano? Recuperado el 4 de enero de 2018, de SOMOSEMPRENDEDORES by Claro: https://somosemprendedores.byclaro.com.ec/como-obtener-la-calificacion-de-artesano/

UNESCO. (20 de marzo de 1997). Codificación de la ley de defensa del artesano. Obtenido de La Organización de las Naciones Unidas para la Educación, la Ciencia y la Cultura: http://www.unesco.org/culture/natlaws/media/pdf/ecuador/ecuador_codificacion_ley_defensa_art esano_20_03_1997_spa_orof.pdf 
Yanchapaxy Jacho, F. X. (2015). Análisis de las estrategias comerciales del sector lácteo-yogurt en supermercados del cantón Quito desde el año 2011 hasta junio del 2014. Quito: Escuela Politécnica Nacional. 